\title{
Variability of exotic ginger (Zingiber officinale Rosc.) accessions for quality parameters
}

\author{
P. Anisha Babu*, N.K. Leela ${ }^{1}$, J. Venkatesh and D. Prasath ${ }^{1}$ \\ College of Horticulture, University of Horticultural Sciences, Udyanagiri, Bagalkot-587 104, Karnataka, India \\ ${ }^{1}$ ICAR-Indian Institute of Spices Research, Kozhikode-673 012, Kerala, India
}

(Manuscript Received: 08-03-2021, Revised:12-04-2021, Accepted: 07-05-2021)

\begin{abstract}
Ginger (Zingiber officinale Rosc.) is one of the important and widely used spices throughout the world in fresh and dried forms. The study on quality characterization and essential oil profiling of 13 ginger genotypes was conducted at ICAR-Indian Institute of Spices Research, Kozhikode, Kerala, during 2019-2020. The genotypes included eight promising exotic accessions (Acc. 393, Acc. 607, Acc. 736, Acc. 833, Acc. 869, Acc. 872, Acc. 873 and Acc. 874), four popular cultivars (Nadan, Himachal, Maran, Riode-Janeiro) and a released variety IISR Varada. Significant differences among the genotypes were recorded for various quality parameters such as oleoresin, essential oil and crude fibre content. Among the exotic genotypes, Acc. 869 recorded the highest essential oil content (2.44\%), followed by Acc. 393 (2.42\%), Acc. 833 and Acc. 873 (2.10\%). The accessions, Acc. 869, Acc. 874 , Acc. 873 and Acc. 393 recorded higher oleoresin content of 5.88 per cent, 5.63 per cent, 5.34 per cent and 5.28 per cent, respectively. Considering essential oil and oleoresin contents, the exotic accessions, Acc. 873, Acc. 393 and Acc. 869 were identified as promising genotypes. Among the other genotypes, Rio-de-Janeiro recorded the highest essential oil (2.76\%) and oleoresin content (6.69\%). The exotic genotypes, viz., Acc. 607, Acc. 736 and Acc. 393 recorded crude fibre content of less than 5 per cent whereas, Acc. 869 recorded the maximum of 7.85 per cent. Fifty compounds were identified through essential oil profiling, and the major classes were sesquiterpene hydrocarbons followed by monoterpene hydrocarbons. The major compound identified was $\alpha$-zingiberene and was highest in Acc. 393 (30.49\%), followed by Maran (30.32\%).
\end{abstract}

Keywords: Crude fibre, GC-MS analysis, ginger, oil profile, oleoresin, zingiberene

\section{Introduction}

Ginger (Zingiber officinale Rosc.), $2 \mathrm{n}=(2 \mathrm{x})=22$, a monocotyledon belonging to the family Zingiberaceae, is a major spice and medicinal plant that originated in South-East Asia and was later introduced to many parts of the globe (Purseglove et al., 1981; Burkill, 1996; Park and Pizutto, 2002; Parthasarathy et al., 2011). It is a perennial herbaceous but grown as an annual, erect, having many fibrous roots, aerial shoots with leaves and modified underground stem (Ravindran et al., 2005).

Ginger has been used as a medicine in Indian, Chinese, and Arabic herbal traditions since ancient times (Kizhakkayil and Sasikumar, 2011). In addition, it possesses the potential to prevent and manage many diseases due to the bioactive compounds viz., gingerols and shogaols (Mao et al., 2019). Moreover, it imparts flavour and pungency to food and beverages. The characteristic organoleptic properties of ginger are contributed by the volatile oil and non-volatile compounds. The essential oils and oleoresin have great importance in export markets. Ginger rhizomes contain essential oil (1 to $2.7 \%$ ), oleoresin (3.9 to $9.3 \%$ ), crude fibre (4.8 to $9.8 \%$ ), and starch (40.4 to $59 \%$ ) (Natarajan et al., 1972) in addition to protein and minerals. The hydro-distilled volatile oil of ginger is a combination of monoterpenes, oxygenated monoterpenes and sesquiterpenes; their relative proportions depend on the genotype and are influenced by geographical locations (Sharma et al., 2002; Raina et al., 2005).

*Corresponding Author: anishababup95@gmail.com 
Ginger is multiplied vegetatively and thus have limited chances for crop improvement through conventional breeding. In such a species, the extent of diversity will be too narrow unless the sample is drawn from diverse agro-climatic conditions (Ravindran et al., 2005). There are numerous studies on the quality attributes and oil profiling of ginger. Still, most of them are restricted to the assessment and selection of naturally occurring clonal variations of indigenous types. Pandotra et al. (2015) reported that different genotypes from different regions were distinct genetically and chemically. Hence, the study was undertaken to identify the variability of quality parameters among the promising exotic genotypes, which is vital to the ginger improvement program.

\section{Materials and methods}

\section{Plant material /genotypes}

The experimental materials were drawn from different agroclimatic zones, conserved at the National Active Germplasm Site (NAGS) of ICARIndian Institute of Spices Research (ICAR-IISR), Kozhikode, Kerala state, India. Initially, 19 exotic accessions viz., Acc. 17 (Jamaica), Acc. 130 (Nepal), Acc. 393 (Taiwan), Acc. 428 (Jamaica), Acc. 430 (Fiji), Acc. 431 (Fiji), Acc. 578 (Nepal), Acc. 607 (Bhutan), Acc. 736 (Brazil), Acc. 833 (China), Acc. 850 (Malaysia), Acc. 866 (USA), Acc. 867 (USA), Acc. 869 (USA), Acc. 870 (USA), Acc. 871 (Australia), Acc. 872 (Australia), Acc. 873 (Uganda), Acc. 874 (Vietnam), four popular cultivars of ginger in India viz., Nadan, Himachal, Maran and Rio-de-Janeiro, and a released variety IISR Varada were characterized for morphological and yield parameters. Based on the yield, eight high yielding ( $\left.\geq 18 \mathrm{t} \mathrm{ha}^{-1}\right)$ accessions were selected and characterized along with the popular cultivars for quality attributes (dry recovery, essential oil, oleoresin and crude fibre levels) and essential oil profile (Table 1).

\section{Experimental site and field management}

The study was conducted at IISR, Kozhikode, during 2019-2020 in randomized complete block design (RCBD) with two replications. The experimental field was located at $11^{\circ} 36^{\prime} 34^{\prime \prime}$ North latitude and 75 49' $12^{\prime \prime}$ East longitude and $60 \mathrm{~m} \mathrm{MSL}$. The area falls under a warm, humid climate with an
Table 1. List of ginger accessions used for quality analysis

\begin{tabular}{ll}
\hline Genotypes & Country of cultivation \\
\hline Exotic genotypes & Taiwan \\
\hline Acc. 393 & Bhutan \\
Acc. 607 & Brazil \\
Acc. 736 & China \\
Acc. 833 & USA \\
Acc. 869 & Australia \\
Acc. 872 & Uganda \\
Acc. 873 & Vietnam \\
Acc. 874 &
\end{tabular}

\begin{tabular}{ll}
\hline Popular cultivars in India (Check varieties) \\
\hline Nadan (Acc. 21) & Kottagiri, Tamil Nadu \\
Himachal & Landrace from Himachal Pradesh, India \\
Maran & Landrace from Assam, India \\
Rio-de-Janeiro & Introduction from Brazil, popular ginger \\
& cultivar in South India
\end{tabular}

Released variety

IISR Varada clonal selection, released from ICAR-IISR, Kozhikode, India

annual rainfall of $4889.6 \mathrm{~mm}$ spread over 155 rainy days. The mean monthly maximum and minimum temperatures during the cropping period were $32.9^{\circ} \mathrm{C}$ and $23.8^{\circ} \mathrm{C}$, respectively. For the same duration, the maximum and minimum relative humidity recorded were 94.5 per cent (January 2020) and 56.9 per cent (May 2019), respectively. The maximum sunshine hours was recorded during January $2020(7 \mathrm{~h})$, while the minimum was recorded during August 2019 (0.9 h). The location soil type was Ustic humitropept with clay loam texture, acidic ( $\mathrm{pH} 4.4)$ having an organic carbon content 2.3 per cent, phosphorous $12 \mathrm{~kg} \mathrm{ha}^{-1}$, potassium $338 \mathrm{~kg} \mathrm{ha}^{-1}$, calcium $719 \mathrm{~kg} \mathrm{ha}^{-1}$, magnesium $162 \mathrm{~kg} \mathrm{ha}^{-1}$ and zinc $0.6 \mathrm{mg} \mathrm{kg}^{-1}$.

Field planting was carried out during May 2019 with the recommended package of practices (Jayashree et al., 2015). The crop was cultivated as a rainfed crop and harvested after seven months of planting for quality characterization.

\section{Quality parameters}

The quality characterization among the genotypes was undertaken with major biochemical constituents viz., oleoresin, essential oil and crude 
fibre contents. The essential oil profiling was undertaken using GC-MS analysis (Shimadzu QP-2010 gas chromatograph).

\section{Dry recovery}

The dry recovery was determined from peeled sundried (10-12 days) rhizome samples after they attained a moisture level of 10-11 per cent (PPV\&FRA, 2007). The dry recovery per cent was calculated by noting the differences between fresh and dry weight.

\section{Oleoresin}

Dried and powdered rhizome samples were used for oleoresin extraction. Ten grams of sample were transferred to a glass column $(18 \times 500 \mathrm{~mm})$ with a stop cock after packing the column with a cotton plug. For extraction, $50 \mathrm{~mL}$ of acetone was added to the column and allowed to stand overnight. The filtrate was drained into a pre-weighed beaker. After that, $30 \mathrm{~mL}$ of acetone was added to the same column and drained for an hour. The acetone was evaporated at a uniform temperature till the weight of residue became constant. The quantity of oleoresin was estimated gravimetrically (ASTA, 1997).

Oleoresin $(\%)=$ [weight of residue $(\mathrm{g}) /$ weight of sample (g)] x 100

\section{Crude fibre}

Crude fibre content was estimated from dried crushed ginger samples using Fibra plus FES 6 from Pelican equipment. One gram of coarsely ground sample was taken to subsequent digestion with acid $\left(1.25 \% \mathrm{H}_{2} \mathrm{SO}_{4}\right)$ and alkali $(1.25 \% \mathrm{NaOH})$. Initially, the sample was kept at $500{ }^{\circ} \mathrm{C}$ until it started to boil; boiling was continued for 45 minutes at $400{ }^{\circ} \mathrm{C}$ during both acid and alkaline digestion. Then the digested samples were washed with distilled water. Weight of residue was noted after it was free from moisture $\mathrm{CWBA}\left(\mathrm{W}^{1}\right)$. After ashing the dried residue in the muffle furnace at $500{ }^{\circ} \mathrm{C}$, weight was noted until a constant value CWAA $\left(\mathrm{W}^{2}\right)$. Weight loss during combustion in a muffle furnace represents the crude fibre content (ASTA, 1997).

Crude fibre $(\%)=\left[\mathrm{W}^{3} / \mathrm{W}\right] \times 100$

$\left[\mathrm{W}_{3}\right.$ (crude fibre) $=\mathrm{W}_{1}-\mathrm{W}_{2 ;} \mathrm{W}=$ weight of sample taken for estimation (1g)]

\section{Essential oil}

The essential oil was extracted by using Clevenger-type apparatus (ASTA, 1997). Twenty five grams of powdered sample was allowed to continuously boil for 3 hours in a $1000 \mathrm{~mL}$ round bottom flask with $500 \mathrm{~mL}$ of water. The extracted oil was allowed to stand overnight to get clear oil. Next day readings were noted, and the collected oil was stored at $-20{ }^{\circ} \mathrm{C}$ after adding a pinch of anhydrous $\mathrm{Na}_{2} \mathrm{SO}_{4}$ to remove the residual moisture for GC-MS analysis.

Essential oil $(\%)=$ [quantity of oil collected $(\mathrm{mL})$ /weight of sample $(\mathrm{g})] \mathrm{x}$ 100

The essential oil yield ( $\left.\mathrm{L} \mathrm{ha}^{-1}\right)$ and oleoresin yield $\left(\mathrm{kg} \mathrm{ha}^{-1}\right)$ was calculated by multiplying the dry yield per hectare of varieties with their respective essential oil and oleoresin contents.

\section{Gas chromatography-mass spectrometry analysis}

GC/MS analysis of oil samples was carried out using Shimadzu GCMS QP 2010 Gas chromatograph equipped with capillary column RtX-5 $(0.25 \mu \mathrm{m} \times 0.32 \mathrm{~mm} \times 30 \mathrm{~m})$. Helium was used as the carrier gas at the flow rate of $1 \mathrm{~mL}$ $\mathrm{min}^{-1}$. The injection port temperature was $250^{\circ} \mathrm{C}$ and the detector temperature $220{ }^{\circ} \mathrm{C}$. The oven was programmed: at $60^{\circ} \mathrm{C}$ for $5 \mathrm{~min}$; up to $110^{\circ} \mathrm{C}$ at $5{ }^{\circ} \mathrm{C} \mathrm{min}{ }^{-1}$, then up to $200{ }^{\circ} \mathrm{C}$ at $3{ }^{\circ} \mathrm{C} \mathrm{min}^{-1}$, again up to $220^{\circ} \mathrm{C}$ at $5^{\circ} \mathrm{C} \mathrm{min}{ }^{-1}$; and finally at $220^{\circ} \mathrm{C}$ for 5 min. (Ionization energy: $70 \mathrm{eV}$; Mass range: 60-450 amu; Split ratio - 1:40).

The constituents of the oil were identified by comparison of retention indices with those reported in Nist 08 library (Stein, 2008) and Wiley library and Mass Spectra (Adams, 2007). Area per cent was accounted as per cent composition of respective compound.

\section{Statistical analysis}

Analysis of variance among the genotypes for different quality parameters such as dry recovery, essential oil, oleoresin and fibre content was done according to Panse and Sukhatme (1989), followed by a post hoc comparison of means using the least significant difference (LSD) test. 


\section{Results and discussion}

Eight high yielding $\left(\geq 18 \mathrm{tha}^{-1}\right)$ exotic accessions were selected and compared with four local cultivars and a released variety for various quality parameters. The genotypes differed significantly for important quality traits such as essential oil, oleoresin and crude fibre except for dry recovery (Table 2).

\section{Oleoresin}

Among the exotic accessions, higher oleoresin content was recorded in Acc. 869 (5.88\%) followed by Acc. 874 (5.63\%), Acc. 873 (5.34\%) and
Sasikumar (2009) reported a lower oleoresin content in improved varieties compared to primitive types or landraces.

Oleoresin content mainly depends on the genotype, solvent extraction conditions, state of rhizomes (fresh or dried), the country of origin, agroclimatic regions, harvest season and cultivation practices (Ratnambal et al., 1987; Vernin and Parkanyi, 2005; Connel, 1969). In the present study, all the genotypes were cultivated in a uniform environment; the variability observed among the genotypes for oleoresin might be due to the effect of genotypes, the country of origin or their place of

Table 2. Variability in quality parameters of 13 ginger genotypes

\begin{tabular}{|c|c|c|c|c|c|c|c|}
\hline Genotypes & $\begin{array}{c}\text { Dry recovery } \\
(\%)\end{array}$ & $\begin{array}{c}\text { Dry yield } \\
\left(\mathrm{t} \mathrm{ha}^{-1}\right)\end{array}$ & $\begin{array}{c}\text { Essential oil } \\
(\%)\end{array}$ & $\begin{array}{c}\text { Oleoresin } \\
(\%)\end{array}$ & $\begin{array}{c}\text { Crude fibre } \\
(\%)\end{array}$ & 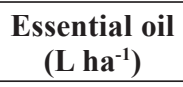 & $\begin{array}{c}\text { Oleoresin } \\
\left(\mathrm{kg} \mathrm{ha}^{-1}\right)\end{array}$ \\
\hline Acc. 393 & 21.56 & 5.24 & 2.42 & 5.28 & 4.25 & 126.88 & 1285.26 \\
\hline Acc. 607 & 17.89 & 5.58 & 1.62 & 3.65 & 3.50 & 90.05 & 1137.28 \\
\hline Acc. 736 & 20.92 & 3.76 & 1.62 & 3.40 & 3.95 & 60.99 & 612.04 \\
\hline Acc. 833 & 19.21 & 4.59 & 2.10 & 5.15 & 5.25 & 96.24 & 1229.80 \\
\hline Acc. 869 & 21.21 & 5.18 & 2.44 & 5.88 & 7.85 & 126.24 & 1433.68 \\
\hline Acc. 872 & 17.77 & 3.34 & 1.62 & 4.61 & 5.05 & 54.07 & 866.72 \\
\hline Acc. 873 & 18.52 & 6.91 & 2.10 & 5.34 & 5.45 & 144.65 & 1995.54 \\
\hline Acc. 874 & 16.95 & 5.43 & 1.64 & 5.63 & 4.85 & 89.65 & 1824.24 \\
\hline Nadan (Acc. 21) & 19.96 & 3.08 & 1.62 & 3.52 & 4.15 & 49.88 & 543.54 \\
\hline Himachal & 19.42 & 2.79 & 2.02 & 4.45 & 4.90 & 56.45 & 639.86 \\
\hline Maran & 22.80 & 3.64 & 2.42 & 6.03 & 6.05 & 88.00 & 961.78 \\
\hline Rio-de-Janeiro & 18.57 & 2.03 & 2.76 & 6.69 & 6.25 & 56.25 & 727.22 \\
\hline IISR Varada & 20.33 & 2.94 & 1.62 & 4.01 & 5.05 & 47.68 & 580.39 \\
\hline Mean & 19.62 & 4.19 & 2.00 & 4.89 & 5.12 & 1087.03 & 13837.35 \\
\hline CD@5\% & NS & 1.31 & 0.15 & 0.09 & 0.55 & 23.47 & 112.29 \\
\hline CV (\%) & NS & 14.31 & 3.34 & 0.89 & 4.90 & 12.89 & 4.842 \\
\hline
\end{tabular}

NS: Non-significant

Acc. 393 (5.28\%), which is significantly higher than the released variety IISR Varada $(4.01 \%)$ and the lowest in Acc. 736 (3.4\%). The health benefits of ginger are mainly due to the phenolic compounds such as gingerols and shogoals (Mao et al., 2019). Among 13 genotypes, the oleoresin content ranged from 3.4 per cent (Acc. 736) to 6.69 per cent (Riode-Janeiro) (Table 2). The highest oleoresin content in Rio-de-Janeiro was also reported by Kallappa et al. (2015) and Akshitha et al. (2020). Kizhakkayil and collection. Therefore the high yielding exotic accessions Acc. 873, Acc. 874, Acc. 869, Acc. 393 and Acc. 833 can be used as potential alternatives for the commercial exploitation of oleoresin.

\section{Crude fibre}

Crude fibre content ranged from 3.5 per cent in Acc. 607 to 7.85 per cent in Acc. 869 (Table 2). Low fibre content varieties are preferred to produce syrup, candy, and other confectionaries. However, 
high fibre content varieties can be used as dry ginger. Latona et al. (2012) observed that high fibre was coupled with therapeutic value in ginger. Among the genotypes, low crude fibre was recorded in exotic accessions such as Acc. 607 (3.5\%), Acc. 736 $(3.95 \%)$, Acc. 393 (4.25\%) and in indigenous genotype, Himachal. High crude fibre content $(>7 \%)$ was recorded in exotic type Acc. 869. All other varieties recorded medium fibre content of 5 to 7 per cent. The crude fibre content of dry ginger ranged from 4.8 to 9.0 per cent, as reported by Natarajan et al. (1972). It also varies with variety, stage of harvesting etc. (Ratnambal et al., 1987; Vernin and Parkanyi, 2005).

\section{Essential oil}

Essential oil content in different genotypes in the present study ranged from 1.62-2.44 per cent (Table 2). Higher oil content of 2.76 per cent was recorded in Rio-de-Janeiro, followed by exotic accessions Acc. 869 (2.44\%) and Acc. 393 (2.42\%). Indigenous cultivar Maran also showed higher oil content of 2.42 per cent. Among the genotypes, lower essential oil content of 1.62 per cent was reported in other genotypes. Earlier reports also recorded a lower essential oil content in IISR Varada (Kizhakkayil and Sasikumar, 2009; Akshitha et al., 2020). Steam distillation of ginger yields 0.2 to 3.0 per cent of essential oil according to the origin and the state of the rhizome (fresh or dried) (Van Beek et al., 1987; Ekundayo et al., 1988). Therefore, high yielding exotic accessions, Acc. 873, Acc. 393 and Acc. 869 can be of much use in the commercial exploitation of essential oil for food, nutraceutical, cosmetic, pharmaceutical and perfume industries.

\section{Gas chromatography-mass spectrometry analysis}

The chemical composition of 13 ginger genotypes was identified and quantified by GC/MS analysis (Table 3 \& Fig.1). Total 50 compounds were identified in oil profiling of the present investigation and grouped into different classes of organic compounds: monoterpene and sesquiterpene hydrocarbons, monoterpenols, sesquiterpenols, esters, aldehydes and ketones. Sesquiterpene hydrocarbons followed by monoterpene hydrocarbons accounted for the major part of essential oils. $\alpha$-zingiberene was the major sesquiterpene, identified in the essential oil of all 13 genotypes. The zingiberene content among the genotypes varied from 19.28 per cent (Himachal) to 30.49 per cent (Acc. 393). The higher zingiberene content was reported in Acc. 393 (30.49\%) followed by Maran (30.32\%) and Acc. 869 (28.92\%). Zingiberene was the major compound in fresh and dry ginger oil (Sasidharan and Menon, 2010). The current results are also in agreement with previous studies where zingiberene was the principal component identified from dry ginger oils (Robbers et al., 1996; Kizhakkayil and Sasikumar, 2011; Choudhari and Kareppa, 2013). The literature revealed that the different genotypes from different regions were distinct both genetically and chemically (Pandotra et al., 2015). It might be the cause of variability for zingiberene among the ginger accessions.

$\beta$-sesquiphellandrene and $\alpha$-farnesene was the second highest compound in most of the genotypes (Table 3). In the present study, $\beta$-sesquiphellandrene content was highest in Acc. 393 (15.39\%) followed by Acc. 869 (14.47\%) and Maran (14.17\%). The lowest sesquiphellandrene content was recorded in Acc. 872 (11.70\%). $\alpha$-Farnesene content varied widely among the genotypes, and the highest was observed in Acc. 833 (15.17\%) followed by Nadan and Himachal (14.52 per cent and 14.05 per cent), respectively. The very low $\alpha$-farnesene content of 4.17 per cent and 4.61 per cent was recorded in Maran and Rio-de-Janeiro, respectively. The higher per cent composition of the same was also reported by Nigam et al. (1964) and Hassanpouraghdam et al. (2011). Ar-Curcumene content among the genotypes varied from 6.61 per cent (Acc. 393) to 9.03 per cent (Rio-de-Janeiro). A high amount of $\alpha$-curcumene and $\beta$-sesquiphellandrene were also detected in all the studied ginger accessions (Kizhakkayil and Sasikumar, 2011). The other major sesquiterpene hydrocarbon compound was $\beta$-bisabolene, which ranged from 2.09 per cent (Acc. 872) to 6.07 per cent (Maran), and most of them showed 2-3 per cent.

Among monoterpene hydrocarbons, camphene content among the genotypes varied from 0.81 per cent (Acc. 874) to 3.42 per cent (Acc. 873); $\beta$-phellandrene (1.68-3.14\%); $\beta$-myrcene and $\alpha$-pinene were also detected in notable amounts. 
(A)

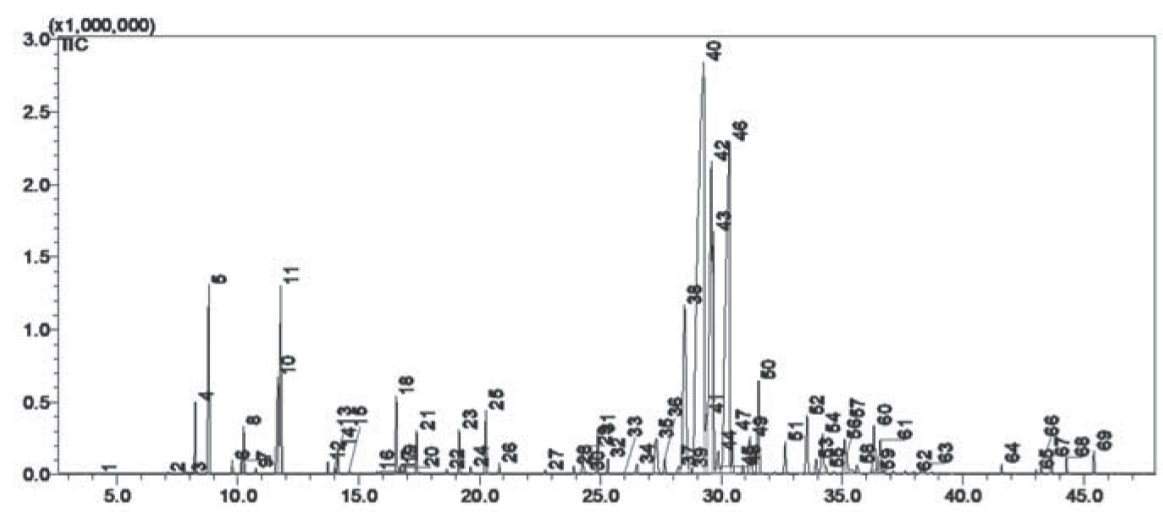

(B)

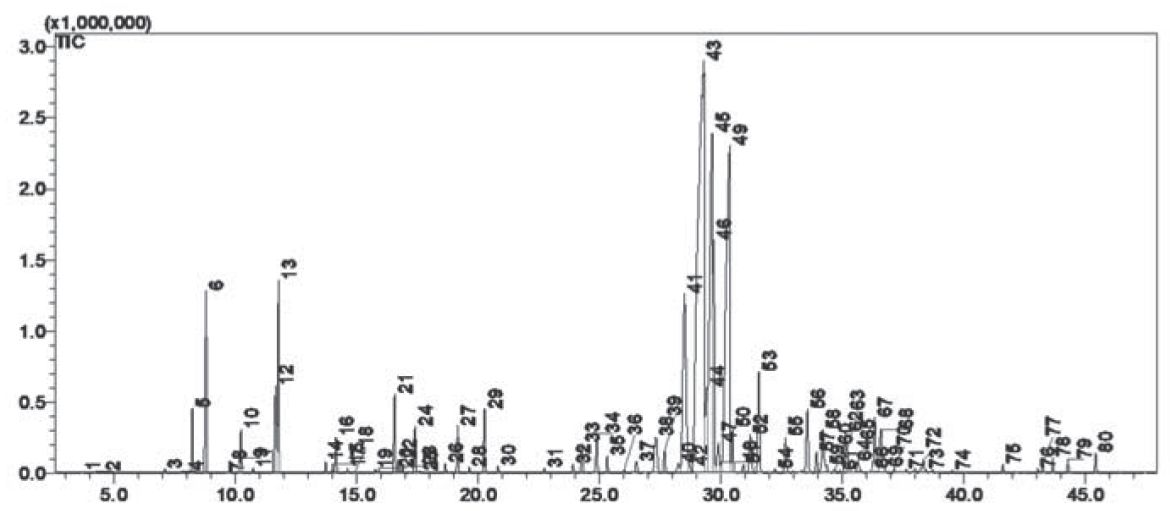

(C)

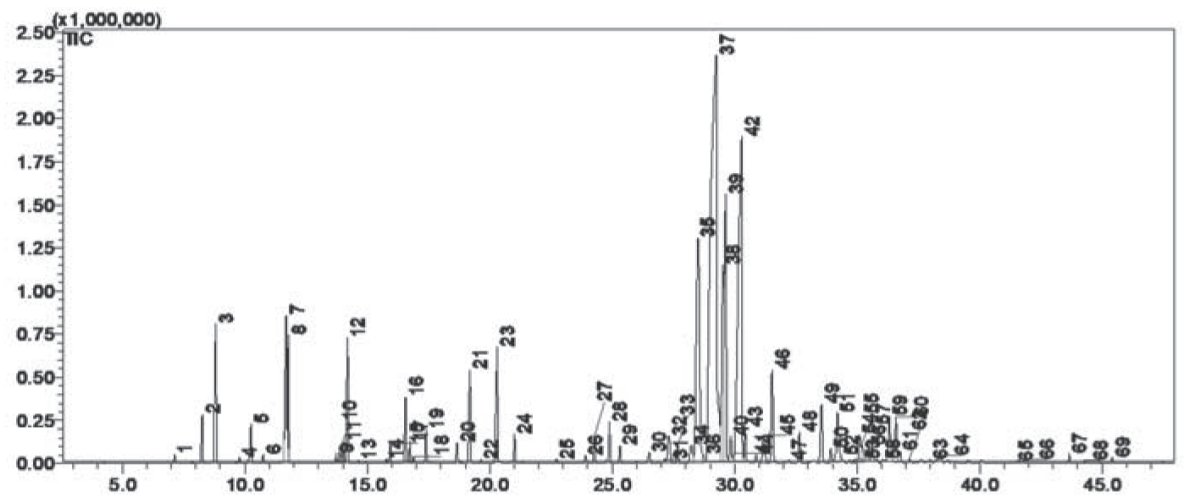

Fig. 1. GC/MS chromatograms of ginger accessions: (A) Acc. 393 (B) Acc. 869; (C) Maran

The 1,8-cineole content ranged from 1.68 per cent (Maran) to 4.2 per cent (Acc. 873). Transnerolidol content in the present study also ranged from 1.89 per cent (Acc. 872) to 3.31 per cent (Acc. 736), which was absent in exotic genotype Acc. 874; neral $(0.47-4.14 \%)$ and geranial $(0.74-5.85 \%)$, collectively referred to as citral, accounted for a notable proportion in the current study and is responsible for the lemon aroma in ginger oil (Onyenekwe and Hashimoto, 1999). The geraniol content varied from 0.53 per cent (Acc. 833) to 2.51 per cent (Acc. 873), which was absent in Acc. 393, 


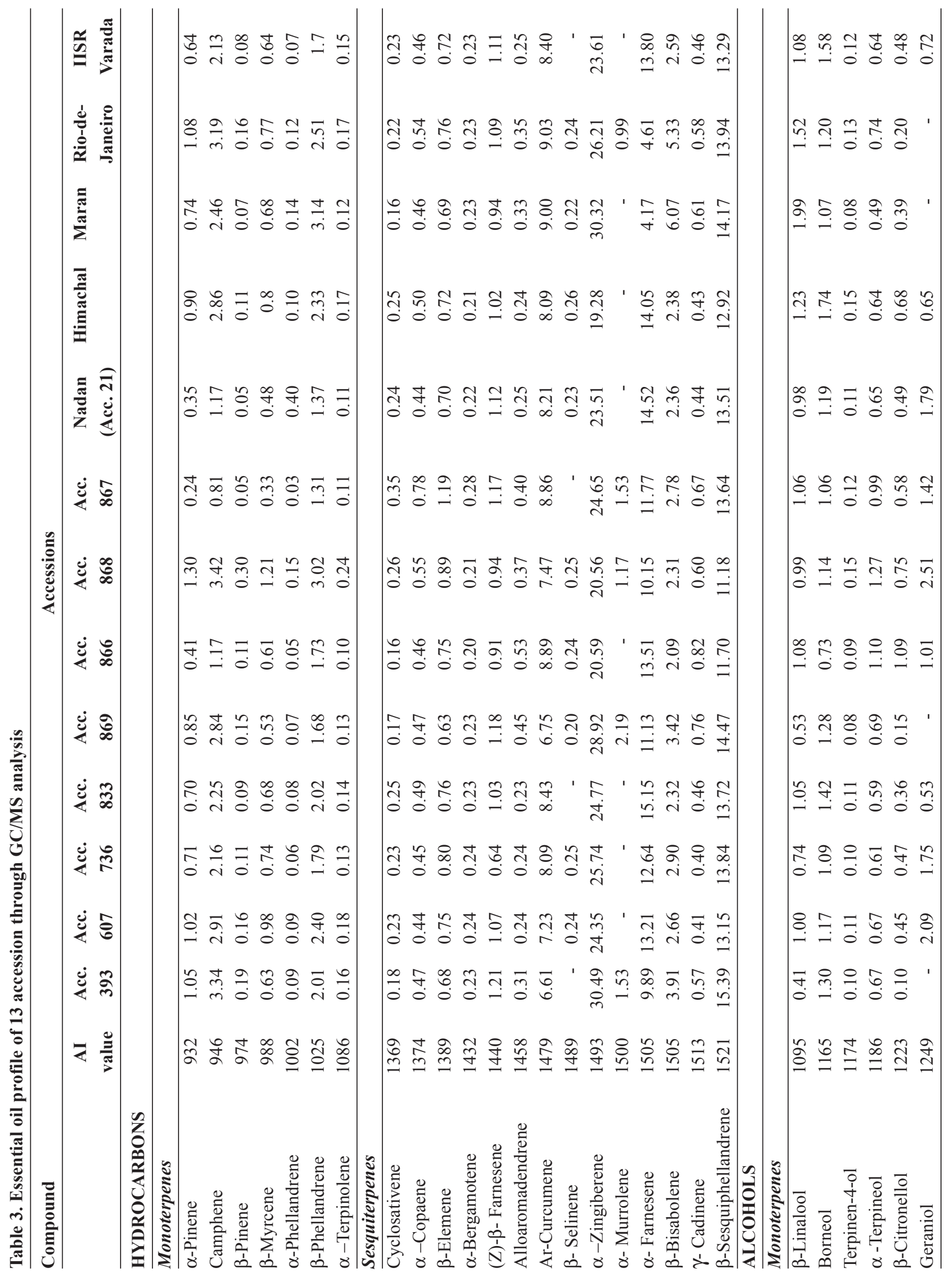




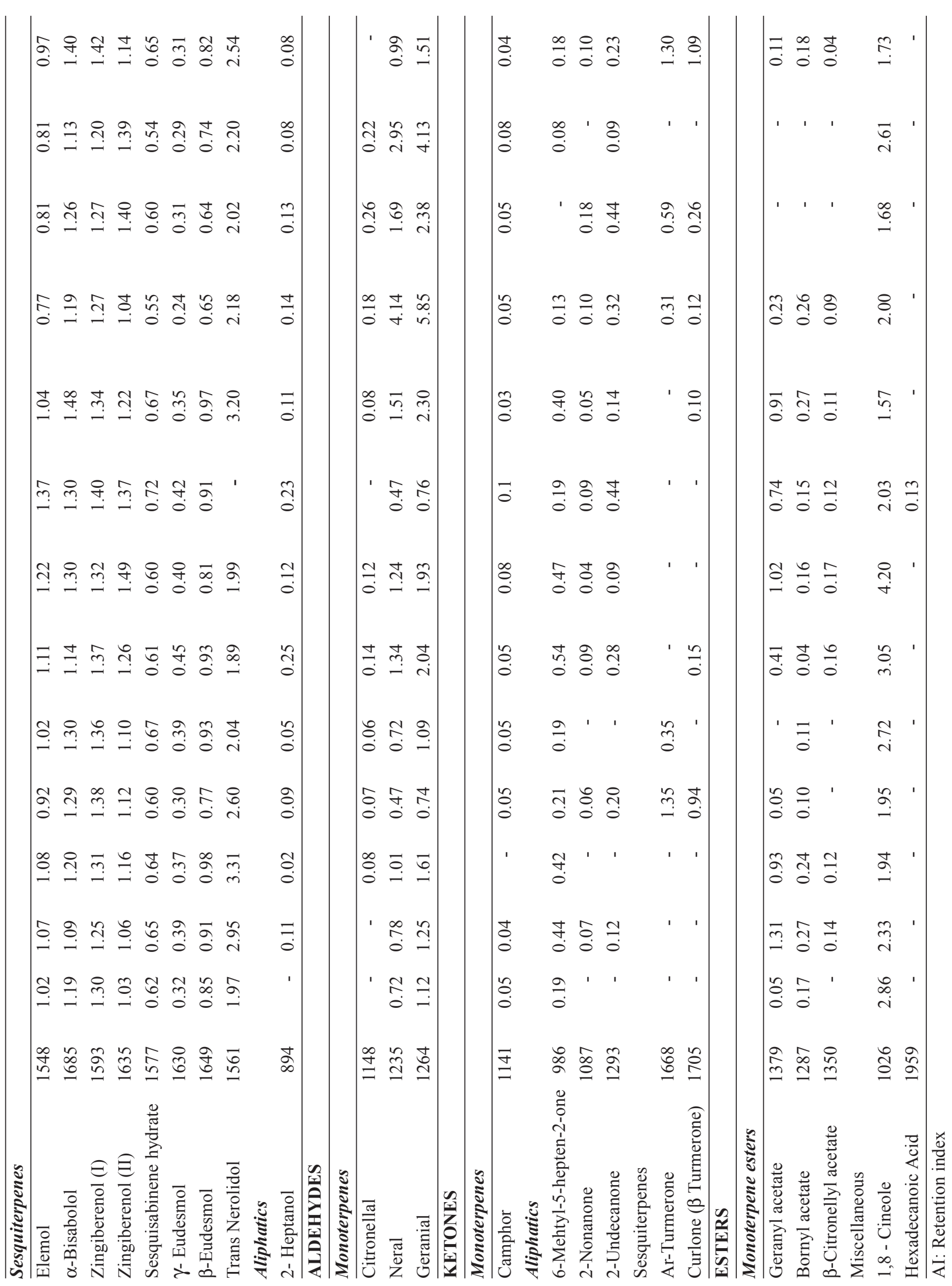


Acc. 833, Maran and Rio-de-Janeiro. Other oxygenated components identified in trace amounts in ginger essential oil were: borneol (0.73-1.74\%); zingiberenol (I) and zingiberenol (II) (1.03-1.49\%); $\alpha$-bisabolol (1.09-1.48\%); elemol (0.77-1.37\%), $\beta$-linalool (0.41-1.99\%), $\alpha$-terpineol (0.49-1.27\%), terpinen-4-ol, citronellal, $\beta$-eudesmol, 2-heptanol, $\gamma$-eudesmol, sesquisebanine hydrate and 6-methyl5-heptene-2-one. Vernin and Parkanyi (1994) had reported the presence of zingiberenol (I), zingiberenol (II) and 6-methyl-5-heptene-2-one from the essential oil of ginger samples while comparing the chemical composition of commercial ginger oils from India and China.

The compounds cyclosativene and alloaromadendrene were observed in very low amounts, i.e., $<0.5$ per cent in all genotypes. Similarly, these compounds were also reported from the hydro distilled essential oil of air-dried ginger from the Iranian herb market (Hassanpouraghdam et al., 2011). The presence of compounds such as; Ar- turmerone was observed in the essential oils of Acc. 833, Acc. 869, Himachal, Maran, IISR Varada and curlone from Acc. 833, Acc. 872, Nadan, Himachal, Maran and IISR Varada.

\section{Conclusion}

The present study identified a considerable extent of variability for various quality parameters among 13 genotypes. The essential oil and oleoresin harvest per hectare were significantly high for some exotic accessions that can be commercially exploited after the multi-location trials at different agroclimatic conditions. The exotic genotypes with lower crude fibre $(<5 \%)$ are suitable for ginger processing industries, and those with higher crude fibre can be useful for dry ginger. Essential oil profiling of the genotypes revealed that sesquiterpene hydrocarbons were the major class of compounds identified, followed by monoterpene hydrocarbons.

\section{Acknowledgement}

The authors thank Director, ICAR-IISR, Kozhikode, Kerala for providing the facilities for carrying out the research work.

\section{References}

Adams, R.P. 2007. Identification of Essential Oil Components by Gas Chromatography/ Mass Spectrometry, $4^{\text {th }}$ Ed. Allured Publishing Corporation, Carol Stream.

Akshitha, H.J., Umesha, K., Leela, N.K., Shivakumar, M.S. and Prasath, D. 2020. Quality attributes and essential oil profiling of ginger (Zingiber officinale Rosc.) genotypes from India. Journal of Essential Oil Research 32(5): 456-463.

ASTA. 1997. Official Analytical Methods of the American Spice Trade Association, $4^{\text {th }}$ Ed. New York.

Burkill, I.H. 1996. A Dictionary of the Economic Products of the Malay Peninsula. Ministry of Agriculture and Cooperatives, Kuala Lumpur, Malaysia. 2444 p.

Choudhari, S.S. and Kareppa, B.M. 2013. Identification of bioactive compounds of Zingiber officinale Roscoe rhizomes through gas chromatography and mass spectrometry. International Journal of Pharmaceutical Research and Development 5: 16-20.

Connel, D.W. 1969. The extraction of ginger. Food Technology in Australia 21: 5: 570.

Ekundayo, O., Laakso, I. and Hiltunen, R. 1988. Composition of ginger (Zingiber officinale Roscoe) volatile oils from Nigeria. Flavour and Fragrance Journal 3(2): 85-90.

Hassanpouraghdam, M.B., Aazami, M.A., Shalamzari, M.S. and Baneh, H.D. 2011. Essential oil composition of Zingiber officinale Rosc. rhizome from the Iranian herb market. Chemija 22(1): 56-59.

Jayashree, E., Kandiannan, K., Prasath, D., Rashid Pervez, Sasikumar, B., Senthil Kumar, C.M., Srinivasan., Suseela Bhai, R. and Thankamani, C. K. 2015. Ginger-Extension Pamphlet. (Eds). Rajeev, P. and Lijo Thomas, IISR, Kozhikode, pp. 1-12.

Kallappa, N., Shetty, G.R., Nagaraj, G., Ravi, P., Sudeep, H.P. and Shivakumar, H.J. 2015. Performance of ginger (Zingiber officinale Rosc.) varieties for yield and quality attributes under hill zone of Karnataka. Ecology, Environment and Conservation 21(3): 259-262.

Kizhakkayil, J. and Sasikumar, B. 2009. Variabilty for quality traits in a global germplasm collection of ginger (Zingiber officinale R.). Current Trends in Biotechnology and Pharmacy 3(3): 254-259.

Kizhakkayil, J. and Sasikumar, B. 2011. Diversity, characterization and utilization of ginger: A review. Plant Genetic Resources: Characterization and Utilization 9(3): 464-477.

Latona, D.F., Oyeleke, G.O. and Olayiwola, O.A. 2012. Chemical analysis of ginger root. Journal of Applied Chemistry 1(1): 47-49.

Mao, Q.Q., Xu, X.Y., Cao, S.Y., Gan, R.Y., Corke, H. and Li, H.B. 2019. Bioactive compounds and bioactivities of ginger (Zingiber officinale Roscoe). Foods 8(6): 185. 
Natarajan, C.P., Bai, R.P., Krishnamurthy, M.N., Raghavan, B., Shankaracharya, N.B., Kuppuswamy, S., Govindarajan, V.S. and Lewis, Y.S. 1972. Chemical composition of ginger varieties and dehydration studies on ginger. Journal of Food Science and Technology 9(3): 120-124.

Nigam, M.C., Nigam, I.C., Levi, L. and Handa, K.L. 1964. Essential oils and their constituents: XXII. Detection of new trace components in oil of ginger. Canadian Journal of Chemistry 42(11): 2610-2615.

Onyenekwe, P.C. and Hashimoto, S. 1999. The composition of the essential oil of dried Nigerian ginger (Zingiber officinale Roscoe). European Food Research and Technology 209(6): 407-410.

Pandotra, P., Gupta, A.P., Khan, S., Ram, G. and Gupta, S. 2015. A comparative assessment of ISSR, RAPD, IRAP, \& REMAP molecular markers in Zingiber officinale germplasm characterization. Scientia Horticulturae 194: 201-207.

Panse, V. G. and Sukhatme, P. V. 1989. Statistical Methods for Agricultural Workers. Indian Council of Agricultural Research, New Delhi, India.

Park, E.J. and Pezzuto, J.M. 2002. Botanicals in cancer chemoprevention. Cancer and Metastasis Reviews 21(3): 231-255.

Parthasarathy, V.A., Srinivasan, V., Nair, R.R., Zachariah, T.J., Kumar, A. and Prasath, D. 2011. Ginger: botany and horticulture. Horticultural Reviews 39: 273-387.

PPV\&FRA. 2007. Guidelines for the conduct of test for Distinctiveness, Uniformity and Stability on ginger (Zingiber officinale Rosc.). Published by Protection of Plant Varieties \& Farmers' Rights Authority (PPV \& FRA), Government of India.

Purseglove, J.W., Brown, E.G., Green, C.L. and Robbins, S.R.J. 1981. Spices Vol. 2. Longman Group Ltd., pp. 447-813.
Raina, V.K., Kumar, A. and Aggarwal, K.K., 2005. Essential oil composition of ginger (Zingiber officinale Roscoe) rhizomes from different place in India. Journal of Essential Oil Bearing Plants 8(2): 187-191.

Ratnambal, M.J., Gopalam, A. and Nair, M.K., 1987. Quality evaluation in ginger (Zingiber offlcinale Rosc.) in relation to maturity. Journal of Plantation Crops 15: 108-117.

Ravindran, P.N., Babu, K.N. and Shiva, K.N. 2005. Botany and crop improvement of Ginger. In: Medicinal and Aromatic Plants Industrial profiles: Ginger, the Genus Zingiber. (Eds.) Ravindran, P.N. and. Babu, K.N., CRC Press, Washington DC. pp. 15-85.

Robbers, J.E., Speedie, M.K. and Tyler, V.E. 1996. Pharmacognosy and Pharmaco-biotechnology, $1^{\text {st }}$ Ed. Williams \& Wilkins, USA, 337 p.

Sasidharan, I. and Menon, A.N. 2010. Comparative chemical composition and antimicrobial activity in fresh and dry ginger oils (Zingiber officinale Roscoe). International Journal of Current Pharmaceutical Research 2(4): 40-43.

Sharma, R.K., Sarma, T.C. and Leclercq, P.A. 2002. Essential oils of Zingiber officinale Roscoe from north east India. Journal of Essential Oil Bearing Plants 5(2): 71-76.

Stein, S.E. 2008. NIST 08 MS Library and MS Search Program (Version 2.0f), National Institute of Standards and Technology, USA.

Van Beek, T.A., Posthumus, M.A., Lelyveld, G.P., Phiet, H.V. and Yen, B.T. 1987. Investigation of the essential oil of Vietnamese ginger. Phytochemistry 26(11): 3005-3010.

Vernin, G. and Parkanyi, C. 1994. Ginger oil (Zingiber officinale Roscoe). In: Spices, Herbs and Edible Fungi. (Ed.) Charalambous, G. Elsevier Science, Amsterdam, the Netherlands, pp. 579-594.

Vernin, G. and Parkanyi, C. 2005. Chemistry of ginger. In: Ginger - The Genus Zingiber. (Eds.) Ravindran, P.N. and Babu, K.N. Boca Raton, FL: CRC Press, Washington DC. pp. $87-180$. 